Martha Lampropoulou ${ }^{1}$

Aristotle University of Thessaloniki удк 811.14'06'367.625

DOI 10.18485/zivjez.2016.36.1.2

Оригинални научни рад

\title{
WORD FORMATION AND RECURRENT PATTERNS IN SUFFIXES IN MODERN GREEK
}

The particular article argues that derivation can be approached via a usage-based cognitive model, proclaiming that conceptual processes motivate grammatical phenomena, as argued by, Brdar (2007), Langacker (2009), Radden and Kövecses (1999) and Ruiz de Mendoza and Galera-Masegosa (2014). Evidence is provided by means of the examination of Modern Greek verbs which delineate how derivation, and in particular suffixation, works. In other words, the study comprises a limited etymological research over two productive and frequent verb suffixes in Greek

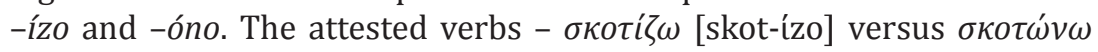
[skotóno],

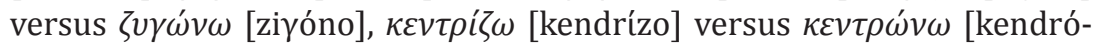

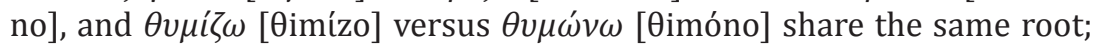
however, the suffixes that are attached to them, namely, -izo and -óno diversify the meaning leading to different scenarios, which occasionally bear a figurative meaning or they arose due to metonymic or metaphoric mappings. What is significant is that the suffixes correlate with specific meanings. For instance, in the specific examples, -ízo correlates with an instrumental meaning; the verb denotes an action where an agent makes use of the entity represented by the stem. Likewise, -óno correlates with a locative meaning or a change of status of the entity which is represented by the stem. The observations concerning the particular examples strengthen the role of the suffix in that it appears to define the meaning of the whole derivative. Last but not least, the study asserts that figuration can play a significant role in suffixation.

Key words: derivation, suffixation, Modern Greek, verbs, analogy, metonymic and metaphoric mappings

1 marthalamp@gmail.com 


\section{Introduction}

The paper addresses derivation mainly through cognition. It examines: a) whether -ízo and -óno are characterized by an instrumental and a locative meaning, respectively, and whether they activate certain 'frames' or scenarios, something which will be explored by studying their etymology. And, lastly, an attempt is made to clarify whether in our examples it is the suffix and/or the base which contributes to the construction of the meaning of the derivative, or both. The derivatives are also motivated by metaphoric or metonymic mappings. For this reason, the study takes into account the "encyclopedic" features of lexical meanings, our imagistic capacity and bodily experience, a proposition held by Langacker. In other words, grammar is considered to be inherently meaningful (Langacker 1987: 1990).

"Grammar, in other words, is basically metonymic, in the sense that the information explicitly provided by conventional means does not itself establish the precise connections apprehended by the speaker and hearer in using an expression." (Langacker 1999: 42)

In the statement above, he accepts the existence of a default interpretation and he expresses it via a metaphor: he compares the explicit linguistic coding to the finding of the right neighborhood, but the finding of the right address is achieved through other less explicit means. These less explicit means are to be attested in the enhancement of our creative abilities via the cognitive mechanisms of metonymy, metaphor, blending, and mental space constructions (Fauconnier 1985; Fauconnier and Turner 2002, Kövecses and Radden 1998, Lakoff and Johnson 1980, Langacker 1999b, Talmy 1996).Within this framework, the theoretical approaches which are basically adopted and presented in the following section are those of Brdar (2007) and Ruiz de Mendoza and Galera-Masegosa (2014) who examine grammaticalization and meaning extension in words/lexemes. Neither approach delves into suffixation. In general, suffixation is an understudied area in Cognitive Linguistics and this is the point where this study contributes in this field. From the two aforementioned approaches, I will stress mostly their propo- 
sitions over grammaticalization, and I will attempt to illuminate suffixation in Modern Greek. For this reason, the follow-up section concerns the relevant literature. Next, section 2 sheds light to suffixation by means of -ízo and -óno. The analysis which accompanies every derivative shows that -izo denotes an instrumental action which also indicates that we have an imminent result and, on the other hand, -óno derivatives display a different meaning, that of 'a change of state or location'. Speculating further on the findings, the derivatives of these two verbal suffixes undergo metaphoric or metonymic processes. Therefore, in a few cases the derivative bears a figurative meaning as the analysis reveals. This confirms the fact that meaning is encyclopedic and non-autonomous and that language conforms to our cognitive capacities, to our cultural views and social norms (Geeraerts 2006: 2-20).

\subsection{Theoretical approaches and characteristics of suffixation}

Prior to exploring the meaning of the Modern Greek derivatives, I would like to refer to three basic key points which concern the morphological process of derivation. Initially, in terms of the Cognitive Linguistics framework, words are viewed as lexical items which are related to certain scenes or frames. In our case, we can assume that a specific meaning not only accompanies the stem, but the suffix, too. For instance, according to Talmy (2000: 66) "a lexical item can specify, in other words, it can incorporate or lexicalize within itself a particular scene partitioning of the event to which it refers". For instance, "the referent of the English verb serve partitions the full situation to which it refers into four main parts: an action, an item served and a social dyad comprising the roles of 'host' and 'guest'" (ibid.). Nevertheless, what is important is the scene that we recall, or better, we conceptualize. Beside the concept of scenes, valency, inheritance, grammaticalization, and analogical thinking are factors that affect suffixation. On top of that, Cognitive Linguists also add the significant role that conceptual processes play in the motivation of grammatical phenomena i.e. suffixation. 
According to Brdar (2007), Lakoff and Johnson (1980), and Langacker (2009) conceptual processes play a crucial role in motivating grammatical phenomena. Thus, their main contribution is that they enable conceptual mappings in order to facilitate understanding and the formation of grammatical constructions.

Briefly, I will present the two main cognitive processes that are involved in the formation of our derivatives of -izo and -óno: metaphor and metonymy.

Metaphor and metonymy are described in a wide number of traditional grammar books, literary and philological ones. However, in the particular study metaphor and metonymy are treated as two main cognitive processes. In the recent literature, metonymy is often contrasted with metaphor. Both processes share a mapping between two concepts. In metonymy, the mapping depends on substitution, a kind of association or relation between the two concepts, while in metaphor the two concepts exhibit a kind of similarity. Based on Lakoff and Johnson (1980: 35), metonymy is: "using one entity to refer to another that is related to it" i.e. The ham sandwich is waiting for his check. The ham sandwich stands for the client who ordered it. On the other hand, an equally famous example of a metaphoric mapping is ARGUMENT IS WAR, underlying phrases such as: He won that argument or I attacked his theory.

In particular, the Cognitive Linguistics enterprise argues that these are conceptual processes, central of our way of thinking as they reveal a knowledge structure (Fauconnier and Turner 2002; Lakoff and Johnson 1999)

However, as mentioned previously it is not only figuration that is involved in morphological processes. Brdar claims that in order to approach grammatical motivation via figurative language, issues such as valency, inheritance, and grammaticalization need to be clarified. It is also important to take into consideration that motivation in relation to grammaticalization might be interpreted differently by various scholars. "What is actually meant by motivation is determined by one's language philosophy and the actual grammatical model adopted" (2007: 37). Overall, the main point is that figurative language optimizes the activation of grammatical structures and processes; that is derivation in our case. Let us review Brdar's key points of grammatical motivation: 


\section{a) valency}

In terms of valency, we need to know that when two constituents are combined they do so because one conforms to the other in terms of syntactic, semantic and phonological properties. "Valency is the capacity of two structures to combine. One significant determinant resides in the phonological and semantic compatibility between the subparts of an expression" (Hamawand 2011: 19).

This complies with the morphological approach proposed by Booj: "complex words inherit formal properties such as morphological class, morphosyntactic class, syntactic category and syntactic valency, from their constituent parts" (Booj 2000: 85). Hence, in the empirical part, we are to expect a special interaction between certain stems and suffixes.

b) inheritance

When inheritance is to be examined, Brdar also stresses that there are times when we cannot clarify why certain morphosyntactic properties are inherited. Brdar makes his point clearer through an example. The verb depend takes the preposition on, and the adjective will also take the preposition on due to analogical thinking (2007: 40). To be more precise, Brdar suggests that since the verb is combined with the preposition on, then, the derivative adjective will most likely be accompanied by the same preposition. The same analogical thinking will affect the morphology not only of derivatives, but also of synonyms of the words in question.

A lexical item partaking of a synonym group will tend to exhibit a similar range of complements as most other items in the group. If any new item is added to the group, either arising through coining, or as a result of metaphorical extension, it will adopt the dominant forms of complements found in the group. (Brdar 2007: 40-41)

For instance, he provides examples with the following adjectives: angry about, mad about, furious about, livid about (ibid.).The same is true for a number of other synonyms such as: keep on, go on, carry on, move on or come in, get in etc.; they inherit the same properties.

Hence, according to Brdar, there is a spectrum where on the one end, we can spot arbitrariness and on the other we can spot 
predictability. Once more, there is fuzziness in setting clear boundaries. Brdar (2007: 41) elaborates on this point [as follows]:

In between these two apparently extreme cases, arbitrariness on the one hand, and predictability of whatever sort on the other, we have a range of cases where the number and form complements are not fully predictable but are nevertheless not entirely arbitrary, since they can be more or less systematically related to some other facts of English grammar and language in general.

c) grammaticalization

The grammaticalization of a linguistic item is related to the notion of motivation. Motivation is a phenomenon exhibited by a range of linguistic structures that are neither wholly arbitrary nor fully predictable. Motivation is also seen as a matter of degree by Langacker (1987: 48) and Lakoff (1987: 346 and 493), who speak of levels of predictability and relative motivation leading to restricted predictions (quoted in Brdar 2007: 42). What is important, though, is that some cases of predictability and motivation can be explained by figurative language, as we will also see in the analysis further below.

An indicative case of motivation of a grammatical phenomenon delineated by Brdar is the grammaticalization of the "going to" construction through metaphorical extension. "The shift of going to from a concrete/lexical to an abstract/grammatical meaning can be shown to have a metaphorical base. Cf. the following set of examples" (2007: 51-52):

(1) a. Jane's going to London (next month)

b. Jane's going to London to work at our office.

c. Jane's going to work at our office.

d. You are going to like her.

e. You're gonna like her.

f. You gonna like her.

By means of these sentences, Brdar points out the shift from the sociophysical world to the epistemic world; an expression of 
motion in the physical world can be used to express intention in the future. At the lexical level, "this phonological erosion following conceptual shift, results in reduced or contracted forms" (Brdar 2007: 53). Another example of grammaticalization concerns the suffix -ize in English; its origin can be traced back in Ancient Greek, when it was initially a verb. Later it was used as a verb suffix which passed in English via loans ${ }^{2}$. To be more specific what it was inherited as a suffix in English, it was a free morpheme in Ancient Greek. In Ancient Greek, the suffix used to serve as an indicative present form i $\zeta \omega$ [ízo] which meant "to make somebody sit, to place, or to lie in wait or lurk" (Vlachou 1996: 327). If we attempt to find any semantic resemblance with the ancient form, we see that the initial meaning is also causative/ resultative and in a way it encloses the current scenario of the suffix -ize that of changing the state of an entity or the location (as in Ancient Greek) i.e. maximize (change of state), hospitalize (change of location).

\section{d) Analogical processes}

It is also important to bear in mind that some morphological processes are motivated by analogy or analogical thinking. This will be exemplified by two examples, one provided by Ruiz de Mendoza and Galera-Masegosa (2014) and the second by Dancygier and Sweetser (2014).

Within the same framework framework as Brdar, Ruiz de Mendoza and Galera-Masegosa (2014) emphasize the motivation of "perceptual phenomena" or linguistic structure. As mentioned previously, the example I borrowed from Ruiz de Mendoza and Galera-Masegosa refer mostly to conversion and figurative language. However, this can serve as evidence for the potential of analogical processes in Greek. The difference may lie in that analogical processes in Greek may appear to suffixes and not to the converted

2 As its etymology reveals (Online Etymology Dictionary): "element used to make verbs, Middle English -isen, from Old French -iser, from Late Latin -izare, from Gree -izein. English picked up the French form, but partially reverted to the correct Greek -z- spelling from late 16c. In Britain, despite the opposition (at least formerly) of OED, Encyclopaedia Britannica, the "Times of London," and Fowler, -ise remains dominant. 
verb since Greek is an inflectional language. To be more explicit, the suffixes that I examine seem to carry a specific meaning which they also attribute to the stem, while in English we can observe that a noun can convert into a verb with zero suffix and this can give rise to similar structures. A characteristic example in English is the structure of Don't X me, where the position of ' $\mathrm{X}$ ' is always taken by a converted verb (Ruiz de Mendoza and Galera-Masegosa 2014: 94).

[C]onsider briefly the constructional framework: Don't X Me, as in Don't honey me! which we have related to a cognitive operation that we call echoing. Echoing involves the repetition of a thought, whether implicit or explicit in the communicative situation. (2014: 11)

Hence, the construction Don't X me originates in a metaphorical mapping that makes use of analogical processes. Instead of honey, the structure could be as follows: don't sweetie me, don't sweetheart me etc. Or with names, i.e don't George me, don't Bernie me.

The phrase will always be metaphorical i.e. when we say to someone "do not honey me", we indirectly connect the sweetness of honey to the attempt of flattering or cajoling a person. Moreover, "this process is licensed by the high-level metonymy RESULT FOR ACTION" (ibid.). The noun is converted to a verb which is used in a resultative manner. The verb honey itself functions as a metonymy since the term of endearment "honey = sweetness" stands for the whole action of cajolery. Based on Radden and Kövecses's typology (1999) this could possibly be labeled a MANNER FOR ACTION metonymic link. In short, both conceptual processes -metonymy and metaphor- motivate the particular structure. Moreover, analogy seems to be pervasive in the aforementioned example. It gives rise to a number of similar examples since the 'Don' $t X m e$ ' structure functions as a replica, or else a recurrent pattern.

Another characteristic example of analogical thinking and figuration is the usage of the suffix -gate. Dancygier and Sweetser employ it referring to blends, but I will borrow it to show how analogy works.

The Watergate Hotel in Washington, DC, has become known worldwide as the site of a break-in which led to a famous political 
scandal, which was known as the Watergate scandal, or simply Watergate. The name of the hotel thus came to evoke the entire frame which resulted from the initial break-in. Ever since, the US media have formed convenient names for political scandals by using the ending -gate (some, like the Monica Lewinsky scandal, were given several -gate names, such as Monicagate, Lewinskygate, Tailgate, and Sexgate). (Dancygier and Sweetser 2014: 97)

The particular case serves as an instance of grammaticalization, if we consider that it triggered a new meaning which was apparently established later since the suffix was used again and again.

Based on these key points raised in the literature, I will examine suffixation by means of --íc [-ízo] and - $\omega v \omega$ [-óno] derivatives.

\section{Derivatives of -ízo and -óno: etymology and recurrent patterns in meaning}

As exemplified previously, suffixes in most languages are characterized by a number of features such as productivity, polysemy, valency (their capacity to combine with certain stems), grammaticalization and analogy. These features were highlighted both by morphological and cognitive approaches. This co-existence of features is also confirmed by the attested derivatives of the current study.

The section presents instances of Ancient Greek nouns that are still in use in Modern Greek. By means of their presentation I would like to show that the meaning of their derivatives of -ízo and -óno is neither fully predictable, nor totally arbitrary. Additionally, the popularity of these two suffixes in Modern Greek, -izo and -óno, seems to be motivated by analogy; the suffixes in our derivatives carry the same meaning. And on top of that, the stems to which they get attached have undergone meaning extension due to the conceptual processes of metaphor and metonymy.

The etymological information that accompanies the examples comes from the Etymological Dictionary of Modern Greek (Babiniotis 2010) and from Triantafyllides online dictionary. The meanings of the Modern Greek verbs explored here are not far from the origi- 
nal meaning of their stem in Ancient Greek. All examples consist of a nominal stem and receive either the suffix -izo or the suffix -óno, resulting in different scenarios, or else, Idealized Cognitive Models. Specifically, the suffix -ízo projects a scene or ICM of 'Use X' (where $\mathrm{X}$ is the stem), and the suffix -óno projects a scene or ICM of 'put into/ put onto $X^{\prime}$ (where $\mathrm{X}$ is the stem).

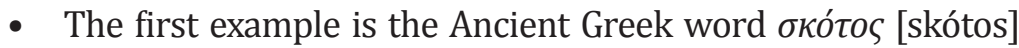
which means a) darkness, total or partial absence of light and b) night The Modern Greek derived verb skot - ízo originally meant 'make dark or darker'3. By means of conceptual metonymy, darkness also symbolizes a 'negative' state because the deprivation of light is related to the unknown. The latter gives rise to fear and frustration and this is the point where the conceptual process of metaphor takes place extending the interpretation to "a dark state of mind, a state of frustration and anxiety": skótos (n) = darkness > skotoúra (n) = trouble, concern or worry. Interestingly, the former meaning, which is 'to make dark', is not currently in use (there is, though, a form si-skot-izo which means the same, that is 'cover with darkness, turn off the light'). However, in Modern Greek the verb bears the definition 'to make somebody experience a state of distress and frustration or worries'. Both thought, the old and the current meaning can be placed under the umbrella label 'Use $\mathrm{X}$ ' i.e 'cover with darkness or give trouble'.

Whereas in skot - óno (with the suffix -óno) the initial meaning was 'to blind', 'deprive of light', , under the umbrella label 'Place into/ onto X', 'place into darkness'. In Modern Greek, it is used metaphorically with the meaning 'to kill'. Here, darkness metonymically represents death; metaphorically somebody puts an individual into a state where s/he can no longer see, or else, s/he experiences death.

Each suffix seems to play a role. However, the meanings of the nominal contribute as well. In the case of skotizo in Modern Greek

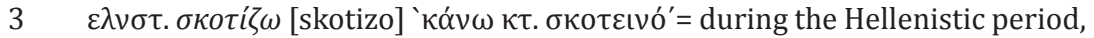
'cover with darkness, darken'

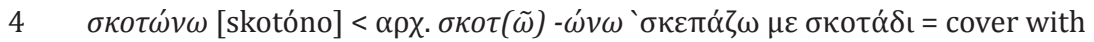
darkness. The etymological information was taken by Triantafyllides online dictionary: http://www.greek-language.gr/greekLang/modern_greek/ tools/lexica/triantafyllides / 
we refer to the act of causing worries, while in the case of skotono we refer to the act of killing. The stem is polysemous.

The noun skotos signifying darkness, both in Greek and in English, can be experienced as night conditions or the darkness everyone experiences when closing one's eyes. These experiences are used via embodied meaning to describe negative emotional state, unawareness or ignorance, and death. Kövecses (2002: 21) notes that light and darkness are "basic human experiences". In other words, darkness may stand for a "dark" state of mind and mood. The exact equivalent phrases can be found in English e.g. a dark mood (Kövecses 2002: 21), the dark side of something or someone, having dark thoughts.

Of course, metaphoric language involves the opposite state; more specifically, HAPPINESS IS LIGHT (Sweetser 1990 and Kövecses 2002: 21), e.g. she brightened up, the darkest hour is just before the dawn (when things are extremely bad, it may be a signal that they are about to get much better).

In addition, in metaphorical expressions like the following, darkness is combined with no sight and, thus, no awareness of a situation.

(2) The committee has kept me in the dark about this matter. [Grady, Oakley and Coulson 1999: 102]

(3) whistle in the dark (to comfort oneself via distraction; to fear the worst and hope for the best). [Urban Dictionary]

In (2) and (3) the conceptual structure from the source domain of vision is employed; in fact, we refer to the absence of vision, darkness. This structure is used to illustrate a scene in the target domain of knowledge and understanding. We refer to the absence of knowledge and awareness: "ignorance is associated with darkness as well as other conditions which preclude sight" (Grady, Oakley and Coulson 1999: 102). Particular elements of the source and target domains are picked out through a combination of the source language used (i.e. in the dark) and the relevant conceptual metaphor, a 'mapping' - presumably retained as knowledge in our longterm memory-which tells us how elements in the two domains line up with each other (ibid.). 
On the other hand, one could argue that this metaphor could be a case of metaphtonymy as it involves a metonymy in its structure. As Goossens (2002) claims metonymy and metaphor are not mutually exclusive and we may have metaphors originating in metonymy; as one could observe in this case, the eyes stand for our ability to see and this can be connected with the notion of awareness at a further mapping. The metonymy here lies in that the eyes are a body part that stands for perception which involves the mind itself.

Finally, the noun skótos via embodied meaning has also been connected metaphorically to the concepts of life and death. In such a context, darkness acquires its most figurative and poetic sense; metaphors such as DARKNESS IS BAD, DARKNESS IS SADNESS and DARKNESS IS DEATH are dominant in poetic discourse cross-culturally. According to Kövecses (2002: 58), death is connected with the disability of seeing, or else, blindness, darkness is connected with the fact of having one's eyes shut for ever. In Greek, such images are common in metaphorical language when speaking of death.

Apparently, the suffixes are mapped with specific scenarios which can also be compared to the concept of an Idealized Cognitive Model. The broader concept of ICMs can adequately be employed to exemplify the particular examples. ICMs constitute a pairing of "things" or "events" the one leading to the other; actually, we speak of a scenario (Radden and Kövecses 1999: 23). The suffixes have a referential function. The suffix -ízo employs a 'Use X' ICM and the suffix -óno employs a 'put into/onto X' ICM. For instance:

\begin{tabular}{|c|c|c|}
\hline Noun & -ízo ('To use X') & Verb \\
\hline 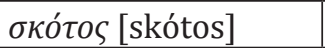 & skot + -ízo & $\sigma \kappa o \tau i ́ \zeta \omega$ [skotízo] \\
\hline $\begin{array}{l}\text { Darkness, meta- } \\
\text { phorically: anxiety, } \\
\text { concern, worries }\end{array}$ & $\begin{array}{l}\text { Negative mood, concerns, } \\
\text { worries (the medium meta- } \\
\text { phorically speaking) } \\
+\quad \text {-ízo: to give trouble (in } \\
\text { an instrumental sense) }\end{array}$ & to trouble \\
\hline
\end{tabular}

Table 1. Depiction of how the specific derivative is formed

Hence, the suffix -ízo builds, or else, motivates a particular interpretation of the derivative, that of 'use X'. In the majority of con- 
temporary Greek morphological analysis of suffixes, there are approaches that indicate the existence of specific semantic features of the Greek verbal suffixes; they are considered to be endowed with a referential role. More specifically, according to Efthymiou (2011) and Efthymiou, Fragaki and Markos (2012), the most prominent meaning of the suffix -ízo is that of 'to use X', where X stands for an entity that functions as an instrument to perform an action:

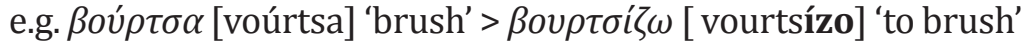
Another meaning is that of 'to make somebody/ something to become X', where X stands for a property, usually a manner

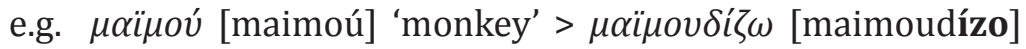
'behave like a monkey in terms of manner-s.

On the other hand, the suffix - óno, is also used as a strong candidate for the meaning of 'to make somebody/ something to become X', where X again stands for a particular behavior, property, or manner:

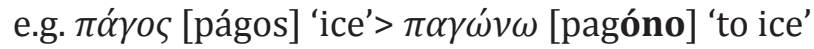

However, -óno can also be used to attribute the meaning of 'put $\mathrm{X}$ into/onto':

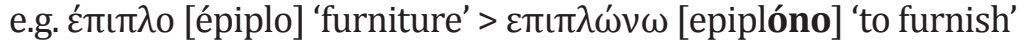

These assumptions are also verified in the following examples. What is also attested is that the usage of -ízo and -óno is related with the meaning extension of the stem due to metaphorical and metonymic mappings; an aspect which the present paper explores.

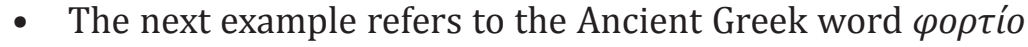
[fortío]: load, cargo, burden, freight. Apart from the physical entity of load, it is used to refer to emotional or psychological discomfort similar to the English conceptualization of load.

Its Modern Greek derivative fort-ízo bears the meaning a) to charge, to cause formation of a net electric charge, b) to energize (a storage battery) by passing current through it and c) to excite; to rouse. In all the previous definitions the meaning of loading is obvious. There is a semantic metonymic shift from the domain of manual labor to the field of electricity to the field of emotions. In all these, the nature of load is different, thus, we conceptualize a different scenario. 
On the other hand, its Modern Greek derivative with -óno, fortóno means 'put a load or large amount of something on or in'. The particular suffix results in a verb with a locative sense and complies with the general semantic sense of the suffix -óno: 'put X into/onto', or else, 'put load into/ onto'.

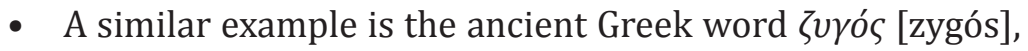
which is defined as a) scale, an instrument for weighing and b) a construction which was part of a chariot or carriage made to keep oxen close together. The first meaning is actually metaphorically constructed based on the image of the mechanism of an ancient chariot. There is a strong imagistic resemblance between an old scale device and an ancient chariot for oxen. As a result, by attaching a different suffix, we resort to different scenarios, each of them highlighting one of the two meanings, respectively.

The Modern Greek derivative zi $\gamma$-ízo means 'use a machine or scale to weigh'. The suffix as a vehicle leads to the ICM 'Use X' which is a clear case of an instrumental verb, 'use a scale'. I would like to add here that 'use a scale' has licensed a metaphorical reading. To put it differently, we use the derivative $\zeta v \gamma i \zeta \omega$ [zi $\gamma$-ízo] in the sense of 'evaluate' or 'weigh possibilities'. As we can witness, the same metaphorical link is possible in English. The verb weigh receives the sense of 'evaluate, consider' as in weigh the consequences.

On the other hand, zi -óno in Modern Greek means 'go close to, approach'. The change of state goes under the ICM of 'Put X into or onto..., 'put under a scale'. The mechanism of the ancient chariot to keep oxen together implies proximity, a sense of approaching. This proximity is the shared similarity with the verb zi $\gamma$-óno, something that delineates a metaphorical conceptual link.
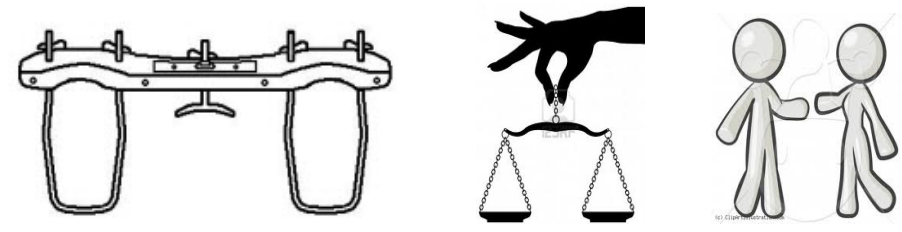

If we compare the images, we can easily distinguish a visual similarity among the pictures, which is reflected on the words. 
Here, apart from the metaphorical mappings we can talk of analogy of thinking.

- Another example provides us with a very interesting story of semantic change of its original meaning. The Ancient Greek word

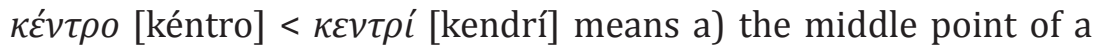
circle or sphere, equidistant from every point on the circumference or surface of an influence, action, force, etc.: the center of a problem b) a point, place, person, etc., upon which interest, emotion, etc., focuses: His family is the center of his life and c) a principal point, place, or object. In all three meanings the image of a central point and a periphery are the shared features in three different domains: geometrical schemata, importance, and a central location in space. This leads to a metaphorical link that something which has a center resembles a circle, or the other way round: something with a periphery has a center.

The Modern Greek verb kendr-ízo means 'to use a sting to sting'. Metaphorically, it means 'to stimulate'. Apparently, both meanings stand for the ICM 'Use X', where $X$ is literally the 'sting', while in the second ' $X$ ' can be anything (anything that works as a sting) that might trigger our attention, emotions, or sensations.

By attaching the suffix -óno to the same stem, the Modern Greek deverbal kendr - óno is formed which means 'to graft, or to engraft'. In other words, "a shoot or twig inserted into a slit on the trunk or stem of a living plant, from which it receives sap"5. The meaning reflects the ICM of 'place into/ onto', and in this case the new branch has to be implanted in a way that it makes contact with the core of the tree trunk, the heartwood; the sense of center can be inferred. Both kendrízo and kendróno seem to share a visual similarity (see pictures ${ }^{6}$ ).
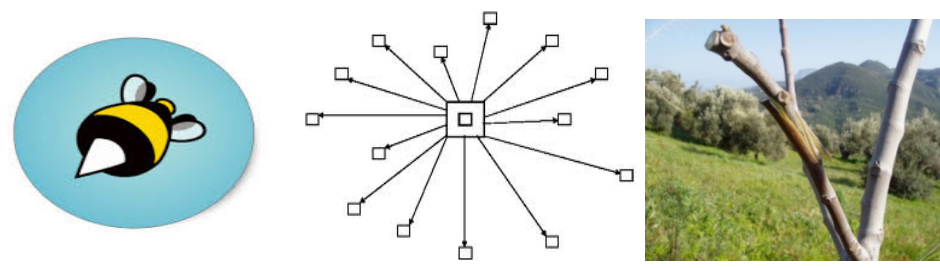

5 Source: https://en.oxforddictionaries.com

6 The pictures were taken from Google Images. 
- The final example is the word $\theta v \mu o$ s [thimós] which in Ancient Greek carried two meanings both of which passed on to Modern Greek ${ }^{7}$. It is an interesting case, as it means a) the emotion of anger and b) memory, reflection and in a broader sense the ability of forming and storing memories. According to the theory of MacLean (1990) the triune brain, a model of the evolution of the forebrain , these two notions -memory and emotions- are linked due to the same location they share in the brain. Even Plato in his works Phaedrus and Republic referring to the parts which compose the soul establishes the same link: the logical, the spirited and the appetitive. Among these three, the spirited and the appetitive which stand for the memory and the desires and emotions, respectively, are established in the same location in the brain. This co-existence is witnessed in the semantics of the derivatives.

The word $\theta v \mu o ́ s$ [ $\theta i m o$ s] in Modern Greek receives the suffix -

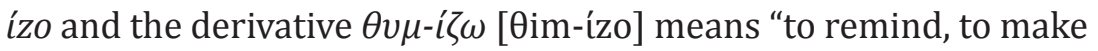
remember or recall" adopting a causative/ resultative sense of 'Use $X$ ', i.e. 'Use the memories, recall the memories'. Whereas the derivative $\theta v \mu-\omega v \omega$ [Өim-óno] means "to get angry", which in a more abstract sense is as if one is put in a different mental state and mindset that of fury, frustration and sudden loss of temper. In other words, the meaning of the suffix could be subsumed in the broader label of 'put into $X$ ', where ' $\mathrm{X}$ ' is a negative emotional state.

\section{Conclusion}

The delineation of these five indicative cases constitutes a sound example that suffixes besides the fact that they are characterized by the features of valency, grammaticalization, and analogical processes, they are also the product of conceptual metonymic and metaphoric extensions in meaning and, on top of that, the suffixes display recurrent patterns in terms of meaning i.e. 'Use X', 'Place into $\mathrm{X}$ '. To put it differently, there is a morphological pattern identified in

7 Actually, the sense of 'memory and reflection' is met in Modern Greek in the

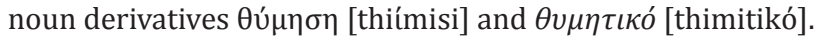


our cases for the specific suffixes used: -ízo and -óno. -ízo leads to a 'Use X' schema, while -óno shows a change of position, a 'put into/ onto $X$ ' schema. Bybee notes that "the psychological restructuring of two words into one depends on the relatedness of the semantic elements being joined and their ability to form a coherent semantic whole" (1983: 29). I will agree with this assumption, since in the current study we can identify a relatedness of the suffixes to be attested and their stems. What seems to be of significance is that the suffix determines the meaning of the derivative, in cases where the stem is characterized by polysemy. The polysemy of the stem involves not only non-figurative but figurative meanings, too. Finally, we could say that suffixes are conceptually dependent on the stem; nevertheless, they display a network of meanings themselves.

Based on the metaphorical or metonymic meaning extensions of the stem, the suffixes determine the meaning of the derivative. The present observations can be fruitful, yet, they concern a limited number of verbs, and a more extended research could be more enlightening. To sum up, the implementation of models developed within Cognitive Linguistics can provide us with additional tools which can be useful in the attempt to decipher morphological processes since they focus on the conceptual aspect of word formation. And by extension, the findings aimed at giving insight into how suffixes are conceptualized and what motivates their usage.

\section{REFERENCES}

Babiniotis, G. (2010). Etymological Dictionary of Modern Greek. Athens.

Booj, G. (2000). 'The Phonology-Morphology Interface', in L. Cheng and R. Sybesma (eds.), The First Glot International State-of-the-Article Book, Berlin: Mouton de Gruyter, 287-306.

Brdar, M. (2007). Metonymy in Grammar: Towards Motivating Extensions of Grammatical Categories and Constructions. Osijek: Josip Juraj Strossmayer University.

Butler, C. S. (2009). The Lexical Constructional Model: Genesis, strengths and challenges. In Deconstructing Constructions. Butler, Christopher S. \& Javier Martín Arista (eds.), 117-152. Amsterdam/Philadelphia: John Benjamins 
Bybee, J. L. (1983). Diagrammatic Iconicity in Stem-inflection Relations. In John Haiman (Ed.) Iconicity in Syntax, Proceedings of a Symposium on Iconicity in Syntax, Stanford, June 24-26, 1983. Amsterdam: John Benjamins.

Dancygier, B. and E., Sweetser (2014). Figurative Language. Cambridge: Cambridge University Press.

Efthymiou, A. (2011). The semantics of verb forming suffixes in Modern Greek. In the Proceedings of the 19th International Symposium of Theoretical and Applied Linguistics, 3-5 April 2009, School of English, Aristotle University of Thessaloniki, 174-184.

Efthymiou, A., Fragaki, G. and Markos, A. (2012). Productivity of verb forming suffixes in Modern Greek: A corpus-based study. Morphology. DOI: $10.1007 / \mathrm{s} 11525-012-9202-4$.

Fauconnier, G. and Turner, M. (2002). The way we think. Conceptual blending and the mind's hidden complexities. New York: Basic Books.

Fauconnier, G. (1985). Mental Spaces: Aspects of Meaning Construction in Natural Languages. Cambridge, MA and London: MIT Press.

Geeraerts, D. (2006). Cognitive Linguistics: Basic Readings. Berlin: Mouton de Gruyter.

Goossens, L. (2002). Metaphtonymy: The Interaction of Metonymy and Metaphor in Expressions of Linguistic Action. In René Dirven and Ralf Pörings (eds.), Metaphor and Metonymy in Comparison and Contrast. Berlin: Mouton de Gruyter, 249-377.

Grady,J.E.,Oakley,T.andS.Coulson(1999). MetaphorandBlending.InG.Steen \& R. Gibbs (eds.), Metaphor in cognitive linguistics,. Philadelphia: John Benjamins.

Hamawand Z. (2011). Morphology in English: Word Formation in Cognitive Grammar. India: Continuum International Publishing Group.

Kövecses, Z. and G. Radden (1998). Metonymy: Developing a cognitive linguistic view. Cognitive Linguistics 9, 33-77.

Kövecses, Z. (2002) Metaphor: A Practical Introduction. New York: Oxford University Press.

MacLean, P. D. (1990). The triune brain in evolution: role in paleocerebral functions. New York: Plenum Press.

Lakoff, G. and M., Johnson (1980). Metaphors we live by. Chicago: University of Chicago Press.

Lakoff, G. and M. Johnson (1999). Philosophy in the Flesh: The Embodied Mind and its Challenges to Western Thought. Chicago: The University of Chicago Press. 
Lakoff G. (1987). Women, Fire and Dangerous Things. Chicago: University of Chicago Press.

Langacker, R. W. (1987). Foundations of Cognitive Grammar. Vol.1: Theoretical Prerequisites. Stanford: Stanford University Press.

Langacker, R. W. (1990). Concept, Image and Symbol: The Cognitive Basis of Grammar [Cognitive Linguistics Research1]. Berlin and New York: Mouton de Gruyter.

Langacker, R. W. (1999b). Virtual Reality. Studies in the Linguistic Sciences, 29, pp. 77-103.

Langacker, R.W. (2009). Metonymic Grammar. In K-U.Panther, L. Thornburg and A. Barcelona (eds.), Metonymy and Metaphor in Grammar. Amsterdam: John Benjamins, 45-71.

Radden, G. and Z., Kövecses (1999). Towards a Theory of Metonymy. In K.U. Panther and G. Radden (eds.), Metonymy in Language and Thought. Amsterdam: John Benjamins, 17-59.

Ruiz de Mendoza I., F. J. and R. U., Mairal (2008). 'Levels of description and constraining factors in meaning construction: an introduction to the Lexical Constructional Model'. Folia Linguistica 42/2 (2008), p. 355-400.

Ruiz de Mendoza I., F. J. and A. Galera-Masegosa (2014). Cognitive Modeling: A linguistic perspective. Amsterdam: John Benjamins.

Sweetser, E. (1990). From Etymology to Pragmatics: The Mind-as Body Metaphor in Semantic Structure and Semantic Change. Cambridge: Cambridge University Press.

Talmy, L. (1996). Fictive Notion in language and "caption". In Bloom et al. (eds.) Language and Space. Cambridge, MA and London: MIT Press, 211-276.

Talmy, L. (2000). Toward a Cognitive Semantics. Cambridge: MIT Press.

Vlachou, V. (1996). Verbs Regular and Irregular of Ancient Greek. [T $\alpha$

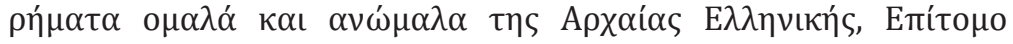
$\Lambda \varepsilon \xi$ ı́ó]. Athens: Gutenberg. 
Martha Lampropoulou

\section{Martha Lampropoulou}

\section{EПАNA $\Lambda$ AMBANOMENA $\Sigma$ XHMATA $\Sigma$ E EПI@HMATA TH $\Sigma$ NEA $\Sigma$ E $\Lambda \Lambda H N I K H \Sigma$ KATA TO $\Sigma$ XHMATI $\Sigma M O ~ \Lambda E \Xi E \Omega N$}

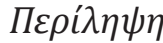

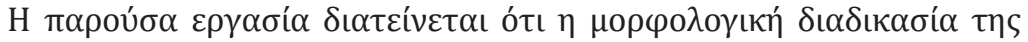

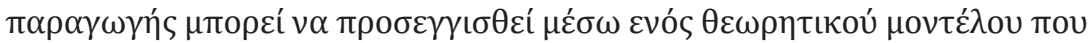

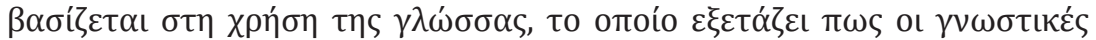

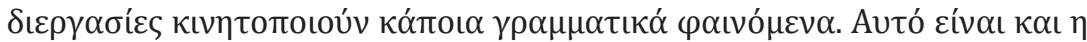

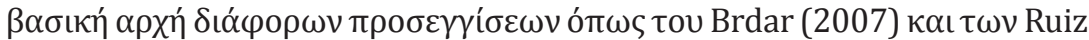

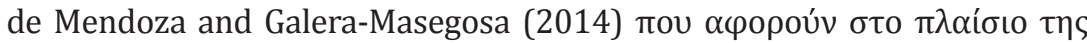

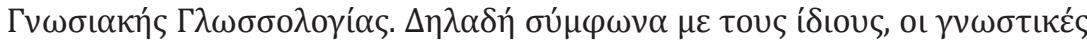

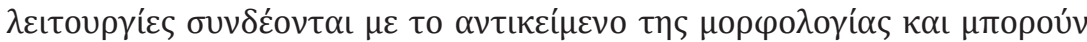

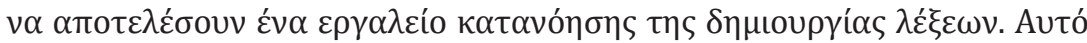

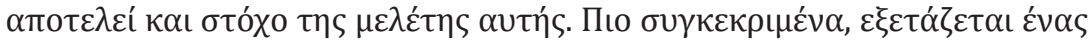

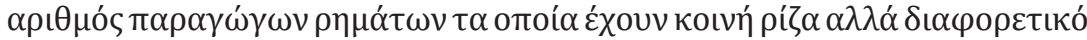

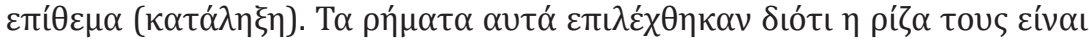

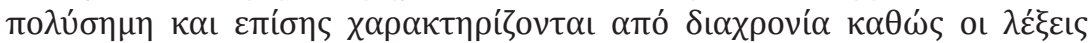

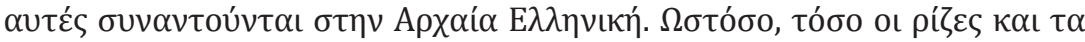

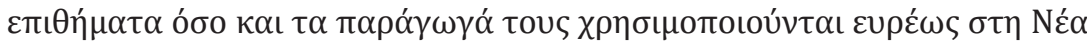

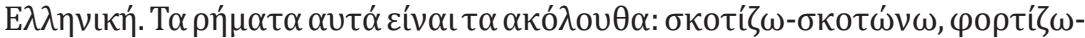


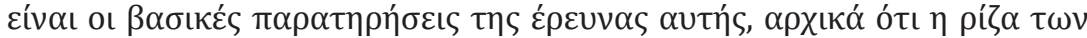

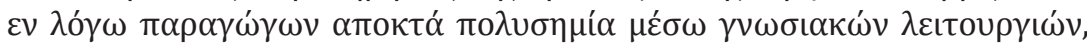

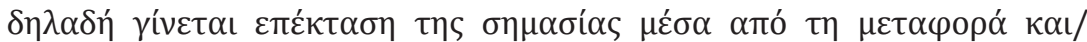

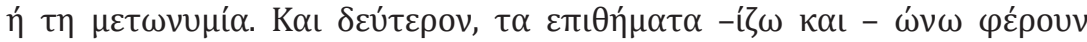

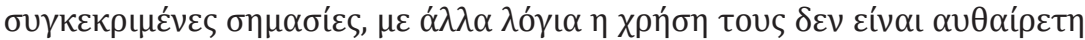

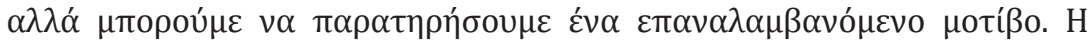

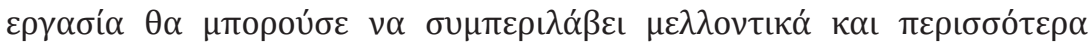

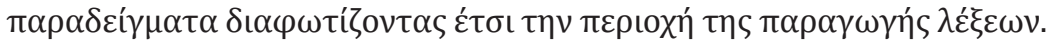

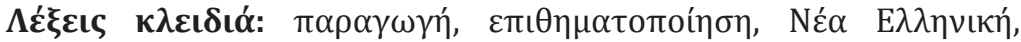

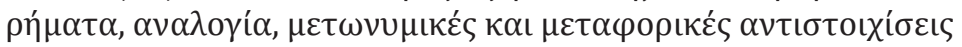

